\title{
Lifestyle patterns on prevention of coronary artery disease among hypertensive clients, attending a tertiary hospital, Kathmandu
}

\author{
Mahato AK' ${ }^{1}$ Onta $\mathrm{M}^{2}$, Mishra TA ${ }^{3}$
}

${ }^{1}$ Anju Kumari Mahato, Instructor, Biratnagar Nursing Campus; ${ }^{2}$ Mandira Onta, Professor and Assistant Dean, TU IOM; ${ }^{3}$ Tulashi Adhikari Mishra, Associate Professor, Maharajgunj Nursing Campus, Maharajgunj, Kathmandu, Nepal.

\begin{abstract}
Background: Hypertension is one of the major risk factors for cardiovascular disease, especially for coronary artery disease. Healthy lifestyles will delay the progression of coronary artery disease.

Objectives: To find out the life style pattern on prevention of coronary artery disease among hypertensive clients.

Methodology: This is a descriptive; cross sectional research design based on quantitative approach. Non probability purposive sampling was used to select 202 respondents attending Outpatient Department at Manmohan Cardiothoracic Vascular and Transplant Centre, Kathmandu. Data was collected by interview technique using semi-structured questionnaire by researcher herself. Descriptive and inferential statistics were used to analyze the data.

Results: Findings of the study showed that $7.90 \%$ of hypertensive clients consumed $\geq 5$ servings of fruits and vegetables per day, whereas $97.52 \%$ were engaged in vigorous intensity work and current tobacco and alcohol consumers were $\mathbf{2 8 . 5 7 \%}$ and $33.80 \%$ respectively. Adherence to all four healthy lifestyle pattern (Diet, Physical Activity, Tobacco Use and Alcohol Consumption) was $32.7 \%$, whereas more than half (58.9\%) of the clients adhered to three lifestyle pattern. There was significant association between dietary pattern, economic status $(p=0.018)$ and ethnicity $(p=<0.001)$; and tobacco use and $\operatorname{sex}(p=<0.001)$.

Conclusion: Adherence to healthy lifestyle pattern of hypertensive clients was inadequate. Thus, health education and other interventions to promote healthy lifestyle pattern are suggested.
\end{abstract}

Key words: Coronary artery disease; Hypertension; Lifestyle pattern

DOI: https://doi.org/10.3126/jkmc.v8i2.28172

\section{INTRODUCTION}

$\mathrm{H}$ ypertension is one of the leading causes of the global burden of disease. Cardiovascular disease risk doubles for every $20-\mathrm{mmHg}$ increase in systolic and $10-\mathrm{mmHg}$ increase in diastolic pressure. Hypertension is often associated with additional cardiovascular disease risk factors, and the risk of cardiovascular disease increases with the total burden of risk factors ${ }^{7}$. Age Adjusted Death Rates per 100,000 Population of hypertension in the United States of America is 14.64, India is 18.52 , whereas in Nepal is $20.77^{13}$.

Address for correspondence

Ms. Anju Kumari Mahato

Instructor, TU IOM Biratnagar Nursing Campus, Biratnagar

E-mail: anjujaisawal@gmail.com
Coronary artery disease (CAD) is a major cause of morbidity and mortality in Nepal. In Nepal the prevalence of hypertension as highest risk factor of coronary artery disease is $35.3 \%$. Majority of risk factors for CAD are modifiable, timely intervention and prevention can help in morbidity and mortality due to this disease ${ }^{6}$.

A healthy lifestyle is a way of living which lowers the risk of being seriously ill ${ }^{14}$. Most of the Non-Communicable Diseases (NCDs) are due to certain lifestyle risk factors like tobacco use, alcohol intake, lack of proper physical activity, lack of proper diet, etc. Each year 7.2 million deaths are due to tobacco, 4.1 million due to excessive salt intake, 3.3 million due to alcohol intake and 1.6 million due to insufficient physical activity ${ }^{15}$. 
Awareness level of hypertensive patients is still low regarding lifestyle. The modification of life style is satisfactory for most risk factors, except for a few like salt intake, additional salty food and number of sticks of cigarettes smoking. So, focus should also be given on modification of lifestyle for reducing the adverse consequences of hypertension' ${ }^{1}$.The overall prevalence of the healthy lifestyle indicator (i.e., having all 4 Healthy Living (haracteristics) was only 3.0\%. Healthy lifestyle defined as a combination of 4 HLCs was undertaken by very few adults in the United States, and no subgroup followed this combination to a level remotely consistent with clinical or public health recommendations ${ }^{10}$.

\section{METHODOLOGY}

Descriptive cross sectional study design based on quantitative approach was adopted for this study. The study setting was Manmohan Cardiothoracic Vascular and Transplant center, Kathmandu, Nepal. Study population was hypertensive clients attending outpatient department. Non-probability Purposive sampling technique was adopted and sample size was 202. Respondents aged 20 to 60 years, with history of having hypertension and diagnosed at least before 6 month were included in the study.

Approval for research and data collection was taken from Research Committee, Maharajgunj Nursing Campus, Institutional Review Board (IRB), and Institute of Medicine. Informed consent was taken from the client and confidentiality was maintained. Data was collected through face to face interview technique using semi structured questionnaire by researcher herself. On an average 8 to 10 clients were interviewed per day and the average time required for an interview was approximately 30 minutes. The data was collected from $2^{\text {nd }}$ July to $28^{\text {th }}$ July, 2017 for a period of 4 weeks. After data collection, informal health teaching was given to client. The collected data was analyzed by using descriptive statistics e.g. Mean, Median, Mode, Standard Deviation and range. Chi-square was used to identify association between lifestyle pattern regarding prevention of CAD and selected variables.

\section{RESULTS}

The mean age of the respondents was $50.37 \pm 9.00$ years. Majority of respondents (82.2\%) were in age group 41 to 60 years. Likewise, female respondents were $64.4 \%$. Based on address, $52 \%$ were from inside the Kathmandu valley. Above half of the respondents (53\%) belonged to Upper caste group and very few (2\%) were Dalit. About two third of respondents (67.37\%) were literate and $28.67 \%$ were bachelor degree completed and above, and $6.61 \%$ were less than primary level. About $36.10 \%$ were homemaker and 9\% were dependent. Approximately two third (63.36\%) of respondents had income enough for twelve months and surplus and $2.97 \%$ had income enough for less than six months. Almost all of the respondents 191 (94.55\%) had history of $\geq 15$ years of hypertension. Among them 196 (97\%) respondents had compliance with the treatment (Table 1).

Regarding diet, 164 (81.18\%) were non vegetarian and $100(60.97 \%)$ consumed chicken. Only 16(7.9\%) of respondents took more than or equal to 5 serving of fruit and or vegetable. About 163(80.69\%) of respondents never took additional salt and nearly half of them i.e. 97 (48.01\%) never took processed food. Likewise, in physical activity of the respondents only 71 (35.14\%) did vigorous intensity work; about $70.79 \%$ of the respondents were sitting less than 23 hours in a week in leisure time. Most of them: 167 (82.67\%) did high physical activity. This study showed $63(31.18 \%)$ of the respondents were using tobacco; among them 18(28.57\%) were current users. About 45(71.42\%) were using smoked tobacco. Regarding alcohol consumption, about $71(35.14 \%)$ of the respondents consumed alcohol and 24(33.33\%) of them were current user.

Overall, lifestyle pattern of the respondents, 76(37.6\%) were taking healthy diet. 197 (97.5\%) were physically active, 184(91.1\%) did not use tobacco currently and only 197(97.5\%) were not consuming alcohol currently. Among all four healthy lifestyle patterns, 66(32.7\%) of respondents adhered to all four healthy life style pattern (Table 6)

This study showed that there is significant statistical association between dietary pattern of the respondents with economic status ( $p$-value 0.018) and ethnicity ( $p$-value<0.001). Similarly, there was association between sex and smoking status ( $p$-value<0.001). Likewise, there was association between educational statuses with alcohol consumption ( $p$-value 0.037). 
Table 1: Respondent's lifestyle pattern: Diet $(\mathbf{n = 2 0 2 )}$

\begin{tabular}{|c|c|c|}
\hline Variables & Number & Percentage \\
\hline \multicolumn{3}{|l|}{ Type of diet } \\
\hline Non-vegetarian & 164 & 81.18 \\
\hline Vegetarian & 38 & 18.81 \\
\hline \multicolumn{3}{|l|}{ Type of meat $(n=164)$} \\
\hline Chicken & 100 & 60.97 \\
\hline Mutton & 42 & 25.60 \\
\hline Buffalo & 14 & 8.53 \\
\hline Fish & 6 & 3.65 \\
\hline Whole egg & 1 & 0.60 \\
\hline Pork & 1 & 0.60 \\
\hline \multicolumn{3}{|c|}{ Frequency of eating meat in a week $(n=164)$} \\
\hline Weekly & 72 & 43.90 \\
\hline Twice weekly & 37 & 22.56 \\
\hline Occasionally & 34 & 20.73 \\
\hline Alternate day & 12 & 7.31 \\
\hline Daily & 9 & 5.48 \\
\hline \multicolumn{3}{|c|}{ Type of cooking pattern ( $n=202$ ) } \\
\hline Shallow frying & 118 & 58.41 \\
\hline Making Gravy & 65 & 32.17 \\
\hline Deep frying & 13 & 6.43 \\
\hline Boiling/steaming & 6 & 2.97 \\
\hline \multicolumn{3}{|l|}{ Types of oil/fat $(n=202)$} \\
\hline Sunflower oil & 116 & 57.42 \\
\hline Mustard oil & 60 & 29.70 \\
\hline Soya bean oil & 21 & 10.39 \\
\hline Maize oil & 3 & 1.48 \\
\hline Butter or ghee & 2 & 0.99 \\
\hline \multicolumn{3}{|c|}{ Intake rate of dairy product $(n=164)$} \\
\hline Daily & 80 & 48.80 \\
\hline Sometimes & 66 & 40.20 \\
\hline Alternate day & 11 & 6.70 \\
\hline Once a week & 4 & 2.40 \\
\hline Twice a week & 3 & 1.80 \\
\hline \multicolumn{3}{|c|}{ Intake of dairy product $(n=164)^{*}$} \\
\hline Milk without Cream & 89 & 54.30 \\
\hline Curd & 57 & 34.80 \\
\hline Milk with Cream & 46 & 28.00 \\
\hline Paneer & 17 & 10.42 \\
\hline
\end{tabular}

${ }^{*}$ Multiple Responses

Table 2: Respondent's lifestyle pattern: Fruits, vegetables and salt

\begin{tabular}{|c|c|c|}
\hline Variables & Number & Percentage \\
\hline \multicolumn{3}{|l|}{ Intake rate of fruit } \\
\hline Occasionally & 82 & 40.60 \\
\hline Daily & 68 & 33.70 \\
\hline Alternate day & 29 & 14.40 \\
\hline Twice weekly & 14 & 6.90 \\
\hline Weekly & 9 & 4.50 \\
\hline
\end{tabular}


Table 2 cont...

No. of fruit serving per day

0 to 3 serving per day

201

99.50

3 to 5 serving a day

$\geq 5$ serving

1

0

0.50

Intake rate of vegetables

\begin{tabular}{lcr} 
Daily & 189 & 93.60 \\
Alternate day & 8 & 4.00 \\
Occasionally & 4 & 2.00 \\
Twice weekly & 1 & 0.50 \\
\hline of vegetable serving per day & & 178
\end{tabular}

0 to 3 serving per day

88.10

3 to 5 serving per day

10.90

$\geq 5$ serving

178

1.00

No. of fruit and vegetable serving per day

0 to 3 serving per day

50.00

3 to 5 serving per day

42.10

$\geq 5$ serving

101

7.90

Additional salt needed

Never

163

80.69

Sometimes

17

8.41

Rarely

17

8.41

Always

5

2.47

Consume processed food

$\begin{array}{lcc}\text { Never } & 97 & 48.01 \\ \text { Sometimes } & 56 & 27.72 \\ \text { Rarely } & 44 & 21.78 \\ \text { Always } & 5 & 2.47\end{array}$

Table 3: Respondent's lifestyle pattern: Physical activities

\begin{tabular}{lcc}
\hline $\begin{array}{l}\text { Variables } \\
\text { Vigorous intensity work(> 3,000 METs minutes/week) }\end{array}$ & Number & Percentage \\
\hline $\begin{array}{l}\text { Yes } \\
\text { No }\end{array}$ & 71 & 35.14 \\
\hline $\begin{array}{l}\text { Moderate intensity work(600-3,000 METs minutes/week) } \\
\text { Yes }\end{array}$ & 131 & 64.85 \\
$\quad$ No & 197 & 97.52 \\
\hline $\begin{array}{l}\text { Sitting hour per week } \\
\quad<23 \text { hours per week }\end{array}$ & 5 & 2.47 \\
$\quad>23$ hours per week & 143 & 70.79 \\
\hline Physical activity per week & 59 & 29.20 \\
$\quad$ High & 167 & 82.67 \\
\hline Moderate & 30 & 14.85 \\
\hline Low & 5 & 2.47 \\
\hline
\end{tabular}


Table 4: Respondent's lifestyle pattern: Tobacco use

\begin{tabular}{|c|c|c|}
\hline Variables & Number & Percentage \\
\hline \multicolumn{3}{|l|}{ Tobacco used } \\
\hline Yes & 63 & 31.18 \\
\hline No & 139 & 68.81 \\
\hline \multicolumn{3}{|c|}{ Tobacco used status ( $n=63$ ) } \\
\hline Current & 18 & 28.57 \\
\hline Former & 45 & 71.42 \\
\hline \multicolumn{3}{|c|}{ If Former year of stop amoking $(n=45)$} \\
\hline$>3$ Years & 33 & 73.33 \\
\hline $0-2$ Years & 12 & 26.66 \\
\hline \multicolumn{3}{|c|}{ Duration exposed to tobacco } \\
\hline$>10$ Years & 39 & 61.90 \\
\hline $0-10$ Years & 24 & 38.09 \\
\hline \multicolumn{3}{|c|}{ Type of tobacco used $(n=63)$} \\
\hline Smoked only & 45 & 71.42 \\
\hline Smokeless only & 12 & 19.04 \\
\hline Both & 6 & 9.52 \\
\hline \multicolumn{3}{|c|}{ Sticks of smoking per day $(n=51)$} \\
\hline$\leq 10$ Sticks & 38 & 74.50 \\
\hline$>10$ sticks & 13 & 25.49 \\
\hline
\end{tabular}

Table 5: Respondent's lifestyle pattern: Alcohol consumption

\begin{tabular}{|c|c|c|}
\hline Variables & Number & Percentage \\
\hline \multicolumn{3}{|l|}{ Alcohol consumption } \\
\hline Yes & 71 & 35.14 \\
\hline No & 131 & 64.85 \\
\hline \multicolumn{3}{|l|}{ Alcohol used status ( $n=71)$} \\
\hline Current & 24 & 33.80 \\
\hline Former & 47 & 66.20 \\
\hline \multicolumn{3}{|c|}{ Frequency of current alcohol intake $(n=24)$} \\
\hline Less than once a month & 16 & 66.70 \\
\hline Daily & 6 & 25.00 \\
\hline 1-3 days per week & 1 & 4.20 \\
\hline 1-4 days per week & 1 & 4.20 \\
\hline \multicolumn{3}{|l|}{ Type of alcohol $(n=24) *$} \\
\hline Local alcohol (Raksi) & 15 & 62.50 \\
\hline Beer/Jaand/Tumba & 7 & 29.16 \\
\hline Wine & 6 & 25.00 \\
\hline Whisky & 3 & 12.50 \\
\hline \multicolumn{3}{|c|}{ Amount of alcohol consumption per day $(n=24)$} \\
\hline 1 Drink & 19 & 79.20 \\
\hline$>1$ drink & 5 & 20.80 \\
\hline
\end{tabular}

*Multiple Responses. 
Table 6: Overall adherence to healthy lifestyle pattern of the respondents

\begin{tabular}{lcc}
\hline Variables & Number & Percentage \\
One of healthy lifestyle pattern & 1 & 0.5 \\
\hline Two of healthy lifestyle pattern & 16 & 7.9 \\
Three of healthy lifestyle pattern & 119 & 58.9 \\
All four of healthy lifestyle pattern & 66 & 32.7 \\
\hline
\end{tabular}

\section{DISCUSSION}

Regarding the dietary pattern, most of the respondents $(81.18 \%)$ were non-vegetarian which is similar to the finding of another study done in Bharatpur which showed slightly lower percentage (i.e. 4\%) of vegetarian ${ }^{11}$. Only $1 \%$ of respondents use ghee in replacement of cooking oil (mustard, soybean, sunflower oil) which is also supported with the finding (2\%) of study done in Sindhuli District ${ }^{4}$. The status of fruit and vegetable intake of respondents in this study were: $99.5 \%$ of them took 0 to 3 serving of fruit per day and $88.1 \%$ took 0 to 3 serving of vegetable per day. Only few of them $(7.9 \%)$ took $\geq 5$ serving of fruit and or vegetable and average consumption was 2.8 servings of fruit and vegetables per day. The finding of the study supported with the various studies, sufficient fruits and vegetables consumption ( $\geq 5$ servings/day) was lacking in $96.6 \%$ of respondents ${ }^{4}$, only $1.1 \%$ of the survey population consumed the recommended five or more servings of fruit and vegetables per day ${ }^{2}$. In contrast $23.3 \%$ of persons consumed fruits and vegetables 5 or more times per day ${ }^{10}$, adequate fruit vegetable consumption was $23 \%{ }^{8}$. Disparity in findings might be due to more awareness in developed countries.

Almost all (97.52\%) of them were engaged in moderate intensity activity and only $2.47 \%$ of the respondents had done low physical activity. The finding of the study inconsistent with the findings of study which showed $11.6 \%$ of respondents were engaged in a moderate level of physical activity,43.3\% exhibited low physical activity ${ }^{12}$, $38.9 \%$ did not participate in any physical activity ${ }^{5}$ and nearly half of respondents (48.8\%) insufficiently ( $\leq 5$ days per week) involved in moderate physical activity ${ }^{4}$. The reason of the difference in finding might be study site and population. This study is confined to hospital based and diseased population, where the respondents may be aware about preventive measures. Regarding tobacco use approximately one third of (31.18\%) the respondents were using tobacco; among them $28.57 \%$ were current user. About $61.9 \%$ of respondents were exposed to tobacco for more than 10 years and $73.33 \%$ stopped taking tobacco more than 3 years prior to the study. About $69.84 \%$ were using smoked tobacco and
$74.50 \%$ used less than 10 sticks per day. More than one third $(35.14 \%)$ of the hypertensive clients consumed alcohol and one third (33.33\%) of them were current user which was higher than other study, that was $17.4 \%$ current drinkers².

About $32.7 \%$ of hypertensive clients adhered to all four healthy lifestyle patterns (i.e. Diet pattern, physical activity, tobacco use and alcohol consumption), whereas, $58.9 \%$ of respondents were adhere to three healthy lifestyle pattern, and few of them (7.9\%) and $(0.5 \%)$ had two and one lifestyle pattern respectively. In contrast, with the study in which only $3 \%$ of the respondents had all four healthy living characteristics, $13.8 \%$ had three healthy living characteristics and 34.2\%, $39.6 \%$, and $9.4 \%$ had two, one and zero healthy living characteristics respectively ${ }^{10}$.Similarly, another study showed only $14.5 \%$ of adolescent, adult, and senior health plan members meet recommended guidelines for four common healthy lifestyle factors and only $10.8 \%$ of adults and $12.8 \%$ of seniors met all five behaviorrelated factors ${ }^{9}$. The contrasting result might have been brought by difference in study population. This study population was confined to specific disease population than above mentioned studies.

In this study, there was significant statistical association between dietary pattern and economic status ( $p=0.018$ ) and ethnicity ( $p=<0.001)$. Study result supported by other study that, socially adjudged higher caste group (Brahman and Chhetri) and upper lower class people ( $p$ $=0.014$ ) had significantly high prevalence of inadequate amount of fruits and vegetables consumption ${ }^{4}$. Likewise, the findings of the study showed that approximately one third of $(31.18 \%)$ of the respondents were using tobacco; among them $28.57 \%$ were current user, showing significant association $(p<0.001)$ between tobacco consumption and sex of hypertensive clients which is supported by various studies; i.e. the overall prevalence of current smoking was $18.5 \%{ }^{2}$, history of current smoking was $38.7 \%{ }^{6}$ and $5.2 \%$ of the respondents reported current cigarette smoking and it was statistically significant with sex $(p<0.001)^{3}$. Similarly, the alcohol consumption was statistically significant with 
educational status ( $p=0.032$ ) which is consistent with the findings of the study which showed, people without formal schooling, had significantly high indulgence to alcohol than others $(p=0.0001)^{4}$.

\section{CONCLUSION}

More than one third of the hypertensive clients are taking recommended diet, but almost all of them are physically active. Few of the hypertensive clients are current tobacco user. Almost all of the clients either did not drink alcohol or drank the recommended standard

\section{REFERENCES}

1. Acharya R, Chalise HN. Life style of patient before and after diagnosis of hypertension in Kathmandu. Health. 2011 Aug 10;3(08):490. [FullText]

2. Aryal KK. Non communicable diseases risk factors: STEPS Survey Nepal 2013. Nepal Health Research Council (NHRC); 2014. [FullText]

3. Awosan KJ, Ibrahim MT, Essien E, Yusuf AA, Okolo AC. Dietary pattern, lifestyle, nutrition status and prevalence of hypertension among traders in Sokoto Central market, Sokoto, Nigeria. International journal of nutrition and metabolism. 2014 Jan 31;6(1):9-17. [FullText]

4. Dhungana RR, Devkota S, Khanal MK, Gurung Y, Giri RK, Parajuli RK et al. Prevalence of cardiovascular health risk behaviors in a remote rural community of Sindhuli district, Nepal. BMC cardiovascular disorders. $2014 \mathrm{Dec} ;$ 14(1):92. [PubMed]

5. Haenle MM, Brockmann SO, Kron M, Bertling U, Mason RA, Steinbach G, Boehm BO, Koenig W, Kern $P$, Piechotowski I, Kratzer W. Overweight, physical activity, tobacco and alcohol consumption in a cross-sectional random sample of German adults. BMC public health. 2006 Dec;6(1):233. [DOI]

6. Kalra S, Narain S, Karki P, Ansari JA, Ranabhat K, Basnet N. Prevalence of risk factors for coronary artery disease in the community in eastern Nepal-a pilot study. JAPI. 2011 May;59:1-2. [PubMed]

7. Kasper DL, Fauci AS, Hauser SL, Longo DL, Jameson JL \& Loscalzo J. Harrison's Principles of Internal medicine $\left(19^{\text {th }}\right.$ ed.) United States of America: Mc Grew Hill Education;2015.

8. Pikala M, Kaleta D, Bielecki W, Maniecka-Bryla I, Drygas W, Kwasniewska M. Awareness of drinks per day. Only one third of the respondents adhered to all four healthy life style pattern (Diet, Physical activity, Tobacco use and Alcohol consumption). There is significant association between dietary pattern and economic status and ethnicity. Tobacco use is significantly associated with sex.

\section{ACKNOWLEDGEMENTS}

The research was supported by University Grant Commission under the Student research grant 2074, for which the researcher is heartily indebted.

cardiovascular prevention methods among residents of post-communist Polish provinces with highest mortality rates. Central European journal of public health. 2011 Dec 1; 19(4):183. [FullText]

9. Pronk NP, Anderson LH, Crain AL, Martinson BC, O'Connor PJ, Sherwood NE, Whitebird RR. Meeting recommendations for multiple healthy lifestyle factors: prevalence, clustering, and predictors among adolescent, adult, and senior health plan members. American journal of preventive medicine. 2004 Aug 1; 27(2):25-33. [FullText]

10. Reeves MJ, Rafferty AP. Healthy lifestyle characteristics among adults in the United States, 2000. Archives of Internal Medicine. 2005 Apr 25;165(8):854-7. [DOI]

11. Twayana RS, Adhikari B, Humagain S, Koju R, Panjiyar R, Rana PVS. Assessment of risk factors for coronary artery disease in patients admitted to college of medical sciences, Bharatpur, Chitwan, Nepal- A Prospective Observational Study. Journal of Cardiology and Clinical Research.2016;4(1):1053 [FullText]

12. Vaidya A, Aryal UR, Krettek A. Cardiovascular health knowledge, attitude and practice/behaviour in an urbanising community of Nepal: a populationbased cross-sectional study from JhaukhelDuwakot Health Demographic Surveillance Site. BMJ open. 2013 Oct 1;3(10):e002976. [DOI]

13. WHO. Global status report on Non Communicable Diseases. (2014). Geneva: WHO. [FullText]

14. WHO. Healthy lifestyle. (2017). Available from: http://apps.who.int/ ris/bitstream 10665/108180/1/ EUR_ICP_LVNG_0 1_07_02 [FullText]

15. WHO. Non communicable diseases. Fact sheet. Geneva: WHO. (2017). [FullText] 